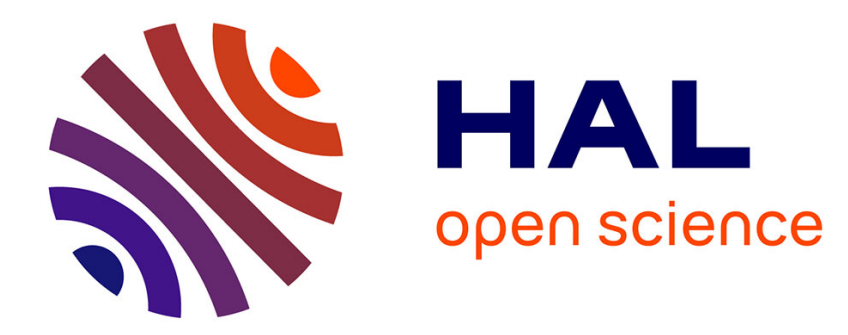

\title{
Forecasting sovereign CDS volatility: A comparison of univariate GARCH-class models
}

Saker Sabkha

\section{To cite this version:}

Saker Sabkha. Forecasting sovereign CDS volatility: A comparison of univariate GARCH-class models. Vie et Sciences de l'Entreprise, 2020, Nº 209 (1), pp.27-56. 10.3917/vse.209.0027 • hal-01769390

\section{HAL Id: hal-01769390 \\ https://hal.science/hal-01769390}

Submitted on 18 Apr 2018

HAL is a multi-disciplinary open access archive for the deposit and dissemination of scientific research documents, whether they are published or not. The documents may come from teaching and research institutions in France or abroad, or from public or private research centers.
L'archive ouverte pluridisciplinaire HAL, est destinée au dépôt et à la diffusion de documents scientifiques de niveau recherche, publiés ou non, émanant des établissements d'enseignement et de recherche français ou étrangers, des laboratoires publics ou privés. 


\title{
Forecasting sovereign CDS volatility: A comparison of univariate GARCH-class models
}

\author{
Saker Sabkha ${ }^{1,2}$, Christian de Peretti ${ }^{1,3}$ and Dorra Hmaied ${ }^{2}$ \\ ${ }^{1}$ Univ Lyon, University Claude Bernard Lyon 1, \\ Institute of Financial and Insurance Sciences, \\ LSAF-EA2429, F-69007, Lyon, France \\ ${ }^{2}$ Univ of Carthage, Institute of High Commercial Studies, \\ LEFA, Tunis, Tunisia \\ ${ }^{3}$ LEO, Université d'Orléans, CNRS, UMR 7322, \\ F-45067, Orléans, France
}

\begin{abstract}
Initially overlooked by investors, the sovereign credit risk has been reassessed upwards since the 2000's which has contributed to awaken the interest of speculators in sovereign CDS. The growing need of accurate forecasting models has led us to fill the gap in the literature by studying the predictability of sovereign CDS volatility, using both linear and non-linear GARCH-class models. This paper uses data from 38 worldwide countries, ranging from January 2006 to March 2017. Results show that the CDS markets are subject to periods of volatility clustering, nonlinearity, asymmetric leverage effects and long-memory behavior. Using 7 heteroskedastic and no heteroskedastic-robust statistic criteria, results show that the fractionally-integrated models outperform the basic GARCH-class models in terms of forecasting ability and that allowing flexibility regarding the persistence degree of variance shocks significantly improves the model's suitability to data. Despite the divergence in the economic status and geographical positions of the countries composing our sample, the FIGARCH and FIEGARCH models are mainly found to be the most accurate models in predicting credit market volatility.
\end{abstract}

JEL Classification: G15, G17, C58.

Keywords: CDS volatility, Predictability, Forecasting models, Loss functions criteria. 


\section{Introduction}

Understanding the fluctuations' dynamic of financial assets has always been of a particular interest in the academic and non-academic spheres. The considerable number of studies focusing on the stock prices' mechanism point out several stylized facts characterizing the financial markets such as: the volatility clustering, the non-stationarity... (See for example Niu and Wang (2013) for a study of the statistical behaviors of the Shanghai Composite Index and Hang Seng Index). Besides the stock markets widely studied, analyzing the characteristics of the credit market, and particularly the sovereign CDS market, is likewise interesting especially when it comes to investigating the impact of financial properties on the suitability of the CDS volatility modeling and forecasting ability.

The curious increase in the empirical studies dealing with modeling CDS data during the last decade can be explained by several reasons: (i) the constantly evolving outstanding amount of the CDS contracts reaching its highest values during the crisis periods, (ii) the need of more clear understanding of the role played by this market in the spread of crises and (iii) and the requirement of identifying the main explaining factors of credit risk. Furthermore, the use of CDS contracts no more as hedging instruments but rather as diversification, trading and speculation instruments has legitimized the usefulness of CDS volatility forecasting to investors for both risk management and portfolio management.

Despite the relevance of the volatility forecasts particularly in the decision process and considering the grown interest in predicting credit spreads, the nonexistence of papers in the literature of CDS spreads dealing with the ability of GARCH models to accurately forecast the volatility of the CDS is completely outrageous ${ }^{[1]}$. The literature on CDS is mainly composed by studies that focus on the determinants of these credit spreads (Oliveira et al., 2012; Costantini et al., 2014; Fontana and Scheicher, 2016) or the Granger Causal relationship between CDS markets and related markets Coudert et al. (2010); Longstaff et al. (2011); Coudert and Gex (2013); Sabkha et al. (2017). The very few papers that investigate the forecasts of CDS spreads (Krishnan et al., 2010; Sharma and Thuraisamy, 2013; Avino and Nneji, 2014; Srivastava et al., 2016) only focus on the first moment order, while the predictability of the CDS volatility remains understudied. Yet, these studies try to forecast the CDS spreads based on the commonly known economic and financial determinants and not based on the predictive ability of the econometric models. Considering the foregoing gaps, this study aims to extent the literature by investigating the forecasting performance of 9 GARCH-class models in the sovereign CDS markets from January $2^{\text {nd }}, 2006$ to March $31^{\text {st }}, 2017$.

Our study contributes to the existing literature in several ways: first, as far a we are concerned, none of the previous studies has focused on the predictability of CDS volatility, especially when it comes to the sovereign market. Second, our paper contributes as well to the literature by implementing a larger set of statistical loss function criteria -taking into account the nonzero mean and the heteroscedasticity of the forecast errors - to assess the out-of-sample predictive ability of the models in comparison with existing forecasting papers on financial assets. Third, the comparative study between linear and non-linear ARCH-class

\footnotetext{
${ }^{[1]}$ The majority of papers dealing with the predictive power of GARCH models, only focus on the major stock indexes and exchange rates (Poon, 2005)
} 
models provides a better and clearer comprehension of the in-sample and out-of-sample fit of the CDS data. Finally, our data set allows us to draw more robust and worldwide conclusions, as it is composed by CDS spreads for 38 countries from all over the world covering the recent two economic and financial crises when the volatility of asset prices have reached their highest unexpected levels.

Our empirical findings show that the sovereign CDS market is characterized by the same stylized facts as the stock market: volatility clustering, leverage effects and long memory behavior. The results of the diagnostic tests on the in-sample modeling generally show that no model outperforms all the others in terms of fitting. Based on the results the 7 loss functions, the predictive performance of the fractionally-integrated models seems to be more accurate, emphasizing the importance of taking into account the long-range memory and the nonlinear behavior of CDS spreads while forecasting volatility. Among the fractionallyintegrated models, our results show that the FIGARCH and the FIEGARCH are the most accurate models, providing the best out-of-sample performances in most cases.

The rest of the paper is organized as follows. A brief literature review of the previous studies predicting financial assets is section 2. Section 3 presents the sample and data used to compare the predictive ability of the models and displays the 9 volatility forecasting models studied. Results of the in-sample and out-of-sample analysis are reported is Section 4. Section 5 concludes the paper.

\section{Literature review}

Investigating the degree to which financial time series can be accurately forecast has always been in the limelight of researchers' issues. The empirical literature on the modeling and predicting volatility processes is extensive and takes into account more and more financial markets properties. Engle (1982) is the first researcher to model financial data through a time-varying stochastic process characterized by a nonconstant correlated variance so-called ARCH model. A generalization of this Autoregressive Conditional Heteroscedaticity model is then proposed by Bollerslev (1986) with more parsimonious and less overparametrization and biasedness in the estimates. Some extensions of this model are afterwards proposed, taking into account more stylized facts of the financial markets: leverage effects (Nelson, 1991; Glosten et al., 1993), stationarity issues (Engle and Bollerslev, 1986), long memory Ding et al. (1993); Baillie et al. (1996); Bollerslev and Mikkelsen (1996); Tse (1998); Davidson (2004)... ${ }^{[2]}$.

These GARCH-class volatility models have been widely used to forecast various financial data, based on their predictive power. The great focus in these studies has been primarily given to stock returns (Keim and Stambaugh, 1986; Poon, 2005; Guidolin et al., 2009; Ferreira and Santa-Clara, 2011; Niu and Wang, 2013), in which recent past information is found to help forecast the future variance. Similar studies are conducted using commodity market data, especially oil data (Agnolucci, 2009; Wei et al., 2010; Chkili et al., 2014; Charles and Darné, 2017). Generally, these studies show no model outperforms all the others in capturing the time series financial and statistical features, while the non-linear GARCH-class models

\footnotetext{
${ }^{[2]}$ For an exhaustive survey of the proposed ARCH-class models, see Poon (2005)
} 
are found to be more relevant in terms of forecasting accuracy ${ }^{[3]}$.

Unlike stock markets, exchange rates and oil market data, not many studies have been conducted to assess the predictive performance of the volatility GARCH-type models using CDS data. Despite Krishnan et al. (2010), Sharma and Thuraisamy (2013), Avino and Nneji (2014) and Srivastava et al. (2016) whose aim is to predict the future changes in the CDS spreads based on some macroeconomic and marketwide variables, the literature on CDS spreads focuses generally on the key drivers and determinants of these credit spreads (Oliveira et al., 2012; Costantini et al., 2014; Fontana and Scheicher, 2016) or rather on the interaction and comovement between CDS markets and the other related financial markets (Coudert et al., 2010; Longstaff et al., 2011; Coudert and Gex, 2013; Sabkha et al., 2017).

Among the first authors who are interested in the prediction of credit spreads, Krishnan et al. (2010) construct credit-spread curves, based on several macroeconomic and firm-specific variables, for 241 highly and lowly credit-risky firms from 1990 to 2005. Results show that only the information contained in the riskless yield curve significantly improve the out-ofsample forecasts. Focusing more precisely on the CDS as proxy for the credit risk level, Sharma and Thuraisamy (2013) investigates the forecastability of the CDS spreads of 8 Asian sovereign from 2005 to 2012. In-sample and out-of-sample evidences reveal that the oil price uncertainty provides valuable information for predicting the future fluctuations in the sovereign CDS spreads. Avino and Nneji (2014) use some economic and financial factors to investigate whether the iTraxx index spreads are forecastle. Based on the results of the predictive ability of some linear (Structural OLS model and AR(1)) and non-linear (Markov-switching) models, these authors show that the daily changes in the CDS index can be predictable from the yield curve, the equity returns and the changes in the VSTOXX volatility index. Using an error correction model before, during and after the subprime crisis, Srivastava et al. (2016) show that the VIX predicts the future changes in $98 \%$ of the studied sovereign CDS markets.

These few studies on the forecastability of CDS spreads rely on the information contained in the theoretical determinants - widely used in the empirical literature - and its ability to predict future fluctuations in the CDS market. Yet, he accuracy of these CDS predictions is assessed through some loss functions criteria that are subject to nonzero mean noise and serial correlation (such as RMSE, MAE...). Furthermore, the data studied so far only cover the period of the subrpime crisis and end before or right after the outbreak of the Sovereign debt crisis, which is quite a weak point given that all the unexpected changes in the market behavior are not taken into account in their forecasting models. Finally, the most important shortcoming of the aforementioned studies, is that they focus on the first moment order neglect the Variance in forecasting the CDS spreads.

\section{Data and methodology}

This section introduces one of our paper contributions: the sample under study, composed by countries around the world, allowing us to provide international evidences and data time

\footnotetext{
${ }^{[3]}$ For a complete theoretical and empirical survey on the use of univariate $\mathrm{ARCH}$ processes in financial studies, see Bollerslev et al. (1992).
} 
line covering the both recent two financial and economic crises. Volatility forecasting models are as well presented in this section.

\subsection{Sample and data description}

Our study focuses on a sample composed by 38 worldwide countries belonging to five different geographical areas: Eastern and Western Europe, North and South America and Asia. Besides the developed countries and the emerging countries, the sample under study in this paper includes some Newly Industrialized Countries (such as Brazil, Mexico, Philippines and Thailand...) and some low economic growth countries with the highest credit risk levels (such as Portugal, Ireland, Greece and Spain...). The sample details with the economic and geographical status of each country are given in Table 1.

The dataset used is composed by daily 5 -year sovereign CDS spreads, denominated in US

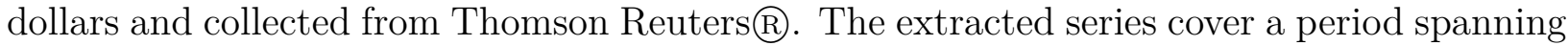
from January 2006 to March 2017, during which the world financial and credit markets have been affected by two major crises, namely the Global Financial Crisis and the Sovereign Debt Crisis. Thus, modeling, forecasting the CDS volatility and comparing models performances are particularly interesting during this period during which we observed some unexpected fluctuations on the credit market.

\subsection{Marginal volatility processes: univariate ARCH-type models}

The financial markets are generally characterized by periods of volatility clustering, during which the assets' second moment order remains high before regaining its normal levels. Engle (1982) proposes an Autoregressive Conditional Heteroscedasticity (ARCH) model able to capture such financial phenomenon. This volatility persistence is as well observed in the Credit Default Swap market and the use of ARCH-class models to model the variance of the CDS spreads is thus legitimate. As an extension of the ARCH model, Bollerslev (1986) proposes a generalized high-order $\mathrm{ARCH}$ process that is more parsimonious and allows for less overparametrization and biasedness in the estimates. This GARCH model is given by:

$$
\begin{gathered}
x_{i, t}=\mu_{i, t}+u_{i, t} \quad / \quad u_{i, t}=\sigma_{i, t} \varepsilon_{i, t}, \quad \varepsilon_{i, t} \mid \mathcal{P}_{t-1} \rightsquigarrow \mathcal{N}(0,1) ; \\
\sigma_{i, t}^{2}=V\left(x_{i, t} \mid \mathcal{F}_{t-1}\right)=\alpha_{i, 0}+\sum_{k=1}^{q_{i}} \alpha_{i, k} a_{i, t-1}^{2}+\sum_{h=1}^{p_{i}} \beta_{i, h} \sigma_{i, t-1}^{2} .
\end{gathered}
$$

with $x_{i, t}$ is a financial time series, $i$ is a given country from the sample and $\mu_{i, t}$ and $\sigma_{i, t}$ are respectively conditional mean and conditional volatility. To satisfy the positive-definite condition, some restrictions are imposed: $p \geq 0, q \geq 0, \alpha_{i, k} \geq 0$ for $k=1, \ldots, q_{i}, \beta_{i, h} \geq 0$ and $\alpha_{i, 0} \geq 0$ for $h=1, \ldots, p_{i}$.

For sake of simplicity and suitability, only models with process orders $\left(p_{i}\right.$ and $\left.q_{i}\right)$ equal to 1 are estimated. In fact, the simplest $\operatorname{GARCH}(1,1)$ specification is the most useful and fitted for financial time series (Bollerslev, 1986; Wei et al., 2010).

The GARCH $(1,1)$ process, as proposed by Bollerslev (1986) is given by the following formula:

$$
\sigma_{i, t}^{2}=\alpha_{i, 0}+\alpha_{i, 1}+\alpha_{i, 1} a_{i, t-1}^{2}+\beta_{i, 1} \sigma_{i, t-1}^{2}
$$


Table 1: Sample and countries classification into economic categories and geographical positions

\begin{tabular}{ll|ll}
\hline \hline Country & Geographical position & Country & Geographical position \\
\hline \hline \multicolumn{2}{c|}{ Developed countries (20) } & \multicolumn{1}{c}{ Newly industrialized countries (6) } \\
Austria & Western Europe & Brazil & South America \\
Belgium & Western Europe & China & Asia \\
Denmark & Western Europe & Mexico & North America \\
Finland & Western Europe & Thailand & Asia \\
France & Western Europe & Turkey & Asia \\
Germany & Western Europe & Emerging countries (11) \\
Ireland & Western Europe & Bulgaria & Eastern Europe \\
Italy & Western Europe & Croatia & Eastern Europe \\
Japan & Asia & Eastern Europe \\
Latvia & Eastern Europe & Hungary & Western Europe \\
Lithuania & Eastern Europe & Greece & Western Europe \\
Netherlands & Western Europe & Indonesia & Asia \\
Norway & Western Europe & Poland & Eastern Europe \\
Portugal & Western Europe & Romania & Eastern Europe \\
Slovakia & Eastern Europe & Russia & Asia \\
Slovenia & Eastern Europe & Ukraine & Eastern Europe \\
Spain & Western Europe & Venezuela & South America \\
Sweden & Western Europe & & \\
UK & Western Europe & & \\
USA & North America & & \\
\hline \hline
\end{tabular}

The countries' economic classification is made according to the NU, the CIA World Factbook, he IMF and the World Bank criteria,

in order to have a sample with a sufficient number of countries in each category.

Furthermore to the previous model restrictions, $\alpha_{i, 1}$ and $\beta_{i, 1}$ parameters must satisfy the condition of $\alpha_{i, 1}+\beta_{i, 1}<1$ to comply with the stationarity in the broad sense.

A more restrictive version of the $\operatorname{GARCH}(1,1)$ is proposed by Engle and Bollerslev (1986) where the equivalent of the unit root in the mean is included in the variance so we can handle for the stationarity of the variance. The Integrated $\operatorname{GARCH}(1,1)$ takes into account the persistence of conditional volatilities ${ }^{[4]}$. The main difference with the $\operatorname{GARCH}(1,1)$ is that the IGARCH requires the parameters $\alpha_{1}$ and $\beta_{1}$ to respect the equality of $\alpha_{1}+\beta_{1}=1$. Thus, the $\operatorname{IGARCH}(1,1)^{[5]}$ can be written as follows:

$$
\sigma_{i, t}^{2}=\alpha_{i, 1} a_{t-1}^{2}+\left(1-\alpha_{i, 1}\right) \sigma_{i, t-1}^{2} .
$$

Besides the aforementioned linear models, there exist some nonlinear GARCH-class of models taking into account the other financial markets properties. The Exponential GARCH,

\footnotetext{
${ }^{[4]}$ Today's shocks on a financial asset (future contracts for example) have a significant impact on the conditional volatility several periods in the future.

${ }^{[5]}$ The IGARCH(1,1) is equivalent to the Exponentially Weighted Moving Average(EWMA) model developed by Morgan (1996).
} 
as proposed by Nelson (1991), is one of these models that accounts for the leverage effect and the asymmetry of the error distribution. While the nonnegativity of linear GARCH model is ensured by several parameters restrictions, the EGARCH model proposes another formulation allowing for a positive volatility without any restrictive constraints. The EGARCH $(1,1)$ is expressed as follows:

$$
\begin{array}{r}
\ln \left(\sigma_{i, t}^{2}\right)=\alpha_{i, 0}+\alpha_{i, 1-1} \ln \left(\sigma_{i, t}^{2}\right)+\beta_{i, 1} g\left(\varepsilon_{i, t-1}\right), \\
\text { where } g\left(\varepsilon_{i, t}\right)=\theta_{i} \varepsilon_{i, t}+\gamma_{i}\left[\left|\varepsilon_{i, t}\right|-E\left(\left|\varepsilon_{i, t}\right|\right)\right] .
\end{array}
$$

The asymmetric relation between assets' fluctuation and volatility changes is depicted by the $\theta_{i}$ and $\gamma_{i}$ representing respectively the sign and the magnitude of $\varepsilon_{i, t}$.

Glosten et al. (1993) propose a model that allows the sign and the amplitude of the innovations $\left(\varepsilon_{t}\right)$ to affect the conditional volatility separately. The asymmetric leverage effect $^{[6]}$ is represented in the following formulation of the GJR-GARCH $(1,1)^{[7]}$ model:

$$
\sigma_{i, t}^{2}=\alpha_{i, 0}+\alpha_{i, 1} a_{i, t-1}^{2}+\gamma_{i} I_{i, t-1} a_{i, t-1}^{2}+\beta_{i, 1} \sigma_{i, t-1}^{2}
$$

with $I_{t}$ is a dummy variable equals to 0 when $a_{t}$ is positive and 1 otherwise.

The first model accounting for the long-range persistence of financial assets variance is developed by Ding et al. (1993). This asymmetric power ARCH model allows the volatility to be long-memory ${ }^{[8]}$. The $\operatorname{APARCH}(1,1)$ model is:

$$
\sigma_{i, t}^{2}=\alpha_{i, 0}+\alpha_{i, 1}\left(\left|a_{i, t-1}\right|-\gamma_{i} a_{i, t-1}\right)^{\delta}+\beta_{i, 1} \sigma_{i, t-1}^{\delta} .
$$

where $\delta$ depicts the Box-Cox power transformation of the conditional volatility $\left(\sigma_{t}\right)$ and satisfies the condition of $\delta \geq 0$.

A more flexible class of GARCH models is proposed by Baillie et al. (1996) who introduce a new feature of the unit root for the variance. In fact, the fractionally integrated GARCH model (FIGARCH) highlights the fact that - unlike stationary processes where the persistence of volatility shocks is finite - in unit root processes, the impact of lagged errors occurs at a slow hyperbolic rate of decay. The FIGARCH model allows, thus, to capture the long memory in financial volatility with a complete flexibility regarding the persistence degree. In fact, the $\operatorname{FIGARCH}(1, \mathrm{~d}, 1)$ formulation depends on fractional integration parameter $(\mathrm{d})$ as follows:

$$
\sigma_{i, t}^{2}=\alpha_{i, 0}+\left[1-\left(1-\beta_{i}(L)\right)^{-1}(1-\phi(L))(1-L)^{d}\right] a_{i, t}^{2}+\beta_{i} \sigma_{i, t-1}^{2} .
$$

with $0<d<1$. When $d=1$, the $\operatorname{FIGARCH}(1, \mathrm{~d}, 1)$ is equivalent to an $\operatorname{IGARCH}(1,1)$ where the persistence of conditional variance is supposed to be complete, while when $d=0$, it is rather equivalent to a $\operatorname{GARCH}(1,1)$ and no volatility persistence is taken into consideration. $\mathrm{L}$ is the lag operator and $(1-L)^{d}$ is the financial fractional differencing operator.

\footnotetext{
${ }^{[6]}$ Positive and negative financial shocks revamp asymmetrically the variance. Furthermore, bad news (shocks) generate greater volatility than good news.

${ }^{[7]}$ The volatility's different reactions to signs and sizes of past innovations are also suggested in the Threshold Heteroskedastic model (TGARCH) of Zakoian (1994). The major difference is that in the TGARCH model the conditional standard deviation $\left(\sigma_{t}\right)$ is considered rather than the conditional variance $\left(\sigma_{t}^{2}\right)$.

${ }^{[8]}$ The autocorrelation function of time series returns decreases gradually.
} 
Other ARCH formulations are extended to the fractionally integrated GARCH, including asymmetric leverage effect presented in the EGARCH model. Bollerslev and Mikkelsen (1996) propose a new class of model combining characteristics of the FIGARCH and the EGARCH models so-called FIEGARCH(p,d,q). Financial assets' volatilities are, thus, better explained and depicted by a mean-reverting fractionally integrated process. The FIE$\operatorname{GARCH}(1, \mathrm{~d}, 1)$ model is written as follows:

$$
\ln \left(\sigma_{i, t}^{2}\right)=\alpha_{i, 0}+\phi(L)^{-1}(1-L)^{-d}[1+\psi(L)] g\left(\varepsilon_{i, t-1}\right) .
$$

where $\phi(L)$ and $\psi(L)$ are lag polynomials, and - as in the $\operatorname{EGARCH}(1,1)^{[9]}-g\left(\varepsilon_{t}\right)$ is a quantization function of information flows such as:

$$
g\left(\varepsilon_{i, t}\right)=\theta_{i} \varepsilon_{i, t}+\gamma_{i}\left[\left|\varepsilon_{i, t}\right|-E\left(\left|\varepsilon_{i, t}\right|\right)\right] .
$$

An extension of the conventional fractionally integrated GARCH model is proposed by Tse (1998) so-called FIAPARCH $(1, \mathrm{~d}, 1)$. The new approach combines the long-range dependencies feature and the asymmetric impact of lagged positive and negative shocks on future volatilities in one fractionally integrated model. The $\operatorname{FIAPARCH}(1, \mathrm{~d}, 1)$ is written as follows:

$$
\sigma_{i, t}^{\delta}=\alpha_{i, 0}\left(1-\beta_{i}\right)^{-1}+\left[1-\left(1-\beta_{i}(L)\right)^{-1} \phi(L)(1-L)^{d}\right]\left(\left|a_{i, t}\right|-\gamma_{i} a_{i, t}\right)^{\delta} .
$$

More recently, another linear GARCH model, called hyperbolic GARCH (HYGARCH) is proposed by Davidson (2004) who argues that the impact of lagged errors on the conditional variance discloses near-epoch dependence feature. The main contribution of this model is that the fractional integration parameter is negative (-d) instead of positive and that $d$ increases rather when it approaches zero ${ }^{[10]}$.The statistical properties included in the HYGARCH make it the most successful and used approach by financial practitioners in modeling time series volatilities. The $\operatorname{HYGARCH}(1, \mathrm{~d}, 1)$ is defined under the following formulation:

$$
\sigma_{i, t}^{2}=\alpha_{i, 0}+\left[1-\left(1-\beta_{i}(L)\right)^{-1}(1-\phi(L))\left[1+\alpha_{i}\left((1-L)^{d}-1\right)\right]\right] a_{i, t}^{2} .
$$

The volatility estimation of the CDS log returns of the 38 countries is computed for 9 GARCH-class models taking into account, each time, different financial stylized facts such as long-run properties in the conditional mean and volatility clustering and long-memory behavior in the conditional variance. The BFGS-BOUNDS method (Broyden, 1970) is used to optimize the likelihood function rather than the conventional numerical optimization, in order to respect the parameters constraints, notably the stationary and the nonnegativity constraints.

In addition to the widely used Box-Pierce tests and the LM ARCH effects test, several other diagnostic tests are reported here, namely the Nyblom test, the adjusted Pearson goodness-of-fit test and the Residual-Based Diagnostic (as suggested by Fantazzini (2011)). The Joint Nyblom (Nyblom, 1989) is a stability test under the null hypothesis of parameters joint constancy over time against the alternative of parameters shift at an undefined

\footnotetext{
${ }^{[9]}$ When the memory parameter, $\mathrm{d}=0$, the FIEGARCH formulation is equivalent to the conventional $\operatorname{EGARCH}(1,1)(\operatorname{FIEGARCH}(1,0,1) \simeq \operatorname{EGARCH}(1,1))$.

${ }^{[10]}$ When $\mathrm{d}$ of the HYGARCH is positive, it is considered as a unit root process.
} 
breakpoint. According to Palm and Vlaar (1997), The adjusted Pearson goodness-of-fit test verifies whether the residuals' empirical distribution matches or not the theoretical distribution (namely Gauss, Student or G.E.D depending on the country). The Residuals-Based Diagnostic test (Tse, 2002) checks for conditional Heteroscedasticity, by complementing and filling the gaps of the Box-Pierce Q statistics.

\subsection{Loss functions criteria}

Following Wei et al. (2010), the forecasting process of the CDS volatility is implemented as follows: the 38 CDS times series' timeline is divided into two subperiods: the in-sample volatility estimation is conducted from January $2^{\text {nd }}$, 2006 to March 31 ${ }^{\text {st }}$, 2014 (2152 observations), and the out-of-sample model forecasts concerns the last three years, i.e. from April $1^{\text {st }}, 2014$ to March 31 ${ }^{\text {st }}, 2017$ (783 observations). The twenty-day out-of-sample forecasting are used to assess and compare the predictive performance of the 9 studied models.

The comparison of the volatility models' forecasting ability is not straightforward. Several measures of the predictive ability are suggested in the literature based on some loss functions. According to Poon (2005), Wei et al. (2010) and Pilbeam and Langeland (2015), we can not conclude with certainty the superiority of one model over another in terms of forecasting performance, based solely on the result of a single error statistic since each criterion may be more and less relevant from one case to another ${ }^{[11]}$. That's why the conclusions made in this study are based on the results of rich set composed by the 7 most popular and relevant ones, including:

- The Mean Square Error (MSE):

$$
M S E=\frac{1}{N} \sum_{t=1}^{N}\left(\hat{\sigma}_{t}-\sigma_{t}\right)^{2},
$$

- The Mean Absolute Error (MAE):

$$
M A E=\frac{1}{N}\left|\hat{\sigma}_{t}-\sigma_{t}\right|,
$$

- The Heteroscedatiscity-adjusted Mean Square Error (HMSE). As suggested by Bollerslev and Ghysels (1996), the HMSE is calculated as follows:

$$
H M S E=\frac{1}{N} \sum_{t=1}^{N}\left(\frac{\sigma_{t}}{\hat{\sigma}_{t}}-1\right)^{2}
$$

- The Heteroscedatiscity-adjusted Mean Absolute Error (HMAE). Andersen et al. (1999) proposes a loss function that better accommodates the heteroskedasticity in the forecast bias. The HMAE is calculated as follows:

$$
H M A E=\frac{1}{N} \sum_{t=1}^{N}\left|\frac{\sigma_{t}}{\hat{\sigma}_{t}}-1\right|,
$$

\footnotetext{
${ }^{[11]}$ Diebold and Mariano (2002) argue that allowing for forecast errors to be non-Gaussian, nonzero mean and autocorrelated produces better tests' results.
} 
- The QLIKE loss fuction (QLIKE). This is a test of forecast bias implied by a Gaussian likelihood (see Wei et al. (2010) for a further details.)

$$
Q L I K E=\frac{1}{N} \sum_{t=1}^{N}\left(L N\left(\hat{\sigma}_{t}\right)+\frac{\sigma_{t}}{\hat{\sigma}_{t}}\right)
$$

- The $\mathrm{R}^{2} \mathrm{LOG}$ loss function $\left(\mathrm{R}^{2} \mathrm{LOG}\right)$ : This loss function asses the goodness-of-fit of the out-of-sample forecasts based on the regressions of Mincer and Zarnowitz (1969)

$$
R^{2} L O G=\frac{1}{N} \sum_{t=1}^{N}\left(L N\left(\frac{\sigma_{t}}{\hat{\sigma}_{t}}\right)\right)^{2}
$$

- The Mean Logarithm of Absolute Errors (MLAE): As proposed Pagan and Schwert (1990), the MLAE criterion is written as follows:

$$
M L A E=\frac{1}{N} \sum_{t=1}^{N} L N\left|\hat{\sigma}_{t}-\sigma_{t}\right|
$$

With $N$ is the number of predicted data and $\hat{\sigma}_{t}$ is the volatility forecasts. The latent daily CDS spreads volatility $\sigma_{t}$ is not observed and is thus proxied by the squared daily logarithmic returns $^{[12]}$. Previous studies (Lopez, 2001; Poon, 2005) report that the use of such a proxy produces unbiased estimates, even though it remains questionable (noisy estimator because of its asymmetric distribution).

\section{Empirical results}

This section presents the summary statistics for the 38 studied time series. The modeling, estimation and testing of the forecasting ability of the 9 GARCH-class models are presented, as well, in this section.

\subsection{Descriptive statistics}

Descriptive statistics, displayed in Table 2, show that the studied countries present dissimilar credit risk levels with CDS spreads ranging from $1 \mathrm{bp}$ to $37081.41 \mathrm{bp}$. The average daily spreads highlights, as well, this divergence in sovereign financing conditions with the largest value recorded, as expected, in Greece (9508.85 bp) and the smallest value recorded in the USA (24.01 bp). The high levels of standard deviations reveal, on the other side, that the worldwide financial and economic troubles impacted the public finances of the countries under study, doubtlessly with different magnitudes. The least volatile CDS market is Germany (24.50). According to the Augmented Dickey-Fuller test (Dickey and Fuller, 1981), all the time series present a unit root, implying that the CDS spreads of the 38 countries are non-stationary at $5 \%$ statistical level at least.

\footnotetext{
${ }^{[12]}$ More methods exist in the literature to proxy the volatility of financial assets, such as, the high-low measure and the realized volatility estimate. For a complete survey of these methods, see Poon (2005).
} 
Table 2: Descriptive statistics and ARCH effect tests for the CDS time series

\begin{tabular}{|c|c|c|c|c|c|c|c|c|c|c|c|c|c|c|c|}
\hline \multirow[b]{3}{*}{ Austria } & \multicolumn{7}{|c|}{ CDS spreads } & \multicolumn{8}{|c|}{ CDS $\log$ returns } \\
\hline & \multirow{2}{*}{$\begin{array}{l}\text { Obs. } \\
2936\end{array}$} & \multirow{2}{*}{$\begin{array}{c}\text { Min } \\
1.40\end{array}$} & \multirow{2}{*}{$\begin{array}{l}\text { Mean } \\
36.13\end{array}$} & \multirow{2}{*}{$\begin{array}{c}\text { Max } \\
132.77\end{array}$} & \multirow{2}{*}{$\begin{array}{r}\begin{array}{c}\text { Std. } \\
\text { Dev }\end{array} \\
24.96\end{array}$} & \multicolumn{2}{|c|}{$\begin{array}{c}\text { ADF } \\
\text { statistics }\end{array}$} & \multicolumn{2}{|c|}{$\begin{array}{c}A R C H-L M \\
\text { (2) }\end{array}$} & \multicolumn{2}{|c|}{$\begin{array}{c}A R C H-L M \\
(5)\end{array}$} & \multicolumn{2}{|c|}{$\begin{array}{c}A R C H-L M \\
(10)\end{array}$} & \multicolumn{2}{|c|}{$G P H$} \\
\hline & & & & & & -2.45 & & 249.75 & $* * *$ & $\overline{127.05}$ & *** & 72.58 & *** & 0.29 & *** \\
\hline Belgium & 2936 & 2.05 & 72.39 & 398.78 & 74.62 & -1.67 & & 508.94 & *** & 237.99 & *** & 120.84 & *** & 0.18 & $* * *$ \\
\hline Brazil & 2936 & 61.50 & 178.55 & 606.31 & 94.86 & -2.46 & & 25.01 & $* * *$ & 43.70 & $* * *$ & 37.71 & *** & 0.11 & $* * *$ \\
\hline Bulgaria & 2936 & 13.22 & 180.37 & 692.65 & 121.88 & -2.25 & & 12.71 & $* * *$ & 10.36 & $* * *$ & 6.72 & $* * *$ & 0.08 & *** \\
\hline China & 2936 & 10.00 & 82.44 & 276.30 & 43.56 & -2.82 & * & 120.85 & $* * *$ & 63.09 & $* * *$ & 39.00 & $* * *$ & 0.22 & $* * *$ \\
\hline Croatia & 2936 & 24.88 & 244.20 & 592.50 & 128.47 & -2.15 & & 137.90 & $* * *$ & 58.87 & $* * *$ & 47.62 & $* * *$ & 0.26 & $* * *$ \\
\hline Czech & 2936 & 3.41 & 66.89 & 350.00 & 49.54 & -2.62 & * & 62.52 & $* * *$ & 46.01 & $* * *$ & 29.50 & $* * *$ & 0.14 & $* * *$ \\
\hline Denmark & 2936 & 11.25 & 36.65 & 157.46 & 32.94 & -2.17 & & 87.27 & $* * *$ & 41.66 & $* * *$ & 24.36 & $* * *$ & 0.21 & $* * *$ \\
\hline Finland & 2936 & 2.69 & 26.85 & 94.00 & 19.24 & -2.33 & & 13.79 & $* * *$ & 7.98 & $* * *$ & 4.43 & $* * *$ & 0.05 & $* * *$ \\
\hline France & 2936 & 1.50 & 54.30 & 245.27 & 50.56 & -1.71 & & 276.95 & $* * *$ & 120.56 & $* * *$ & 62.86 & $* * *$ & 0.20 & $* * *$ \\
\hline Germany & 2936 & 1.40 & 28.77 & 118.38 & 24.50 & -2.05 & & 252.46 & $* * *$ & 128.31 & $* * *$ & 73.27 & $* * *$ & 0.29 & $* * *$ \\
\hline Greece & 2936 & 5.20 & 9508.85 & 37081.41 & 15351.1 & -1.46 & & 5.E-04 & & 4.E-04 & & 6.E-04 & & -4.E-04 & \\
\hline Hungary & 2936 & 17.34 & 225.98 & 729.89 & 153.05 & -2.18 & & 14.48 & $* * *$ & 15.20 & $* * *$ & 8.67 & $* * *$ & 0.10 & $* * *$ \\
\hline Indonesia & 2936 & 118.09 & 219.29 & 1240.00 & 116.83 & -2.63 & * & 139.82 & $* * *$ & 105.31 & $* * *$ & 61.49 & $* * *$ & 0.23 & $* * *$ \\
\hline Ireland & 2936 & 1.75 & 188.89 & 1249.30 & 234.02 & -1.36 & & 218.63 & $* * *$ & 103.01 & $* * *$ & 63.33 & $* * *$ & 0.18 & $* * *$ \\
\hline Italy & 2936 & 5.575 & 151.7504 & 586.7 & 127.38 & -1.79 & & 127.35 & $* * *$ & 60.46 & $* * *$ & 35.18 & $* * *$ & 0.19 & $* * *$ \\
\hline Japan & 2936 & 2.13 & 49.26 & 152.64 & 33.28 & -1.94 & & 71.53 & $* * *$ & 31.30 & $* * *$ & 21.68 & $* * *$ & 0.13 & $* * *$ \\
\hline Latvia & 2936 & 5.50 & 210.89 & 1176.30 & 216.13 & -1.62 & & 152.57 & $* * *$ & 68.47 & $* * *$ & 35.36 & $* * *$ & 0.26 & $* * *$ \\
\hline Lithuania & 2936 & 6.00 & 169.21 & 850.00 & 154.01 & -1.90 & & 56.75 & $* * *$ & 26.91 & $* * *$ & 13.56 & $* * *$ & 0.15 & $* * *$ \\
\hline Mexico & 2936 & 64.17 & 141.89 & 613.11 & 59.36 & -3.03 & * & 356.35 & $* * *$ & 160.17 & $* * *$ & 127.50 & $* * *$ & 0.39 & $* * *$ \\
\hline Netherlands & 2936 & 7.67 & 37.13 & 133.84 & 29.50 & -2.00 & & 10.79 & $* * *$ & 4.33 & $* * *$ & 5.59 & $* * *$ & 0.05 & $* * *$ \\
\hline Norway & 2936 & 10.59 & 30.95 & 62.00 & 17.82 & -1.68 & & 3.22 & $* * *$ & 2.46 & $* * *$ & 2.06 & *** & 0.05 & $* *$ \\
\hline Philippines & 2936 & 78.30 & 188.72 & 840.00 & 101.70 & -1.77 & & 154.83 & $* * *$ & 127.66 & $* * *$ & 90.03 & $* * *$ & 0.23 & $* * *$ \\
\hline Poland & 2936 & 7.67 & 101.35 & 421.00 & 73.12 & -2.32 & & 311.98 & $* *$ & 135.64 & $* *$ & 75.78 & $* *$ & 0.21 & $* * *$ \\
\hline Portugal & 2936 & 4.02 & 289.89 & 1600.98 & 323.68 & -1.60 & & 53.57 & $* * *$ & 42.23 & $* * *$ & 22.61 & *** & 0.17 & $* * *$ \\
\hline Qatar & 2936 & 7.8 & 83.13518 & 390 & 53.89 & -2.12 & & 37.65 & $* * *$ & 17.33 & $* * *$ & 9.55 & *** & 0.09 & $* * *$ \\
\hline Romania & 2936 & 17.00 & 204.20 & 767.70 & 144.17 & -2.09 & & 57.88 & $* * *$ & 33.74 & $* * *$ & 17.50 & $* * *$ & 0.17 & $* * *$ \\
\hline Russia & 2936 & 36.88 & 209.09 & 1106.01 & 147.84 & -2.95 & * & 258.09 & $* * *$ & 117.58 & $* * *$ & 65.50 & $* * *$ & 0.29 & $* * *$ \\
\hline Slovakia & 2936 & 5.33 & 77.52 & 306.01 & 66.71 & -2.03 & & 25.14 & $* * *$ & 24.62 & $* * *$ & 19.31 & $* * *$ & 0.11 & $* * *$ \\
\hline Slovenia & 2936 & 4.25 & 131.24 & 488.58 & 114.88 & -1.65 & & 13.23 & $* * *$ & 9.82 & $* * *$ & 34.88 & $* * *$ & 0.11 & $* * *$ \\
\hline Spain & 2936 & 2.55 & 144.63 & 634.35 & 135.01 & -1.56 & & 195.02 & $* * *$ & 78.80 & $* * *$ & 39.98 & $* * *$ & 0.19 & $* *$ \\
\hline Sweden & 2936 & 1.63 & 27.17 & 159.00 & 25.70 & -2.64 & * & 69.49 & $* * *$ & 30.82 & $* * *$ & 20.72 & $* * *$ & 0.16 & $* * *$ \\
\hline Thailand & 2936 & 51.01 & 120.94 & 500.00 & 41.89 & -3.64 & * & 81.52 & $* * *$ & 120.36 & $* * *$ & 96.33 & $* * *$ & 0.17 & $* * *$ \\
\hline Turkey & 2936 & 109.82 & 217.65 & 835.01 & 72.41 & -3.72 & * & 69.04 & $* * *$ & 86.65 & $* * *$ & 46.84 & $* * *$ & 0.21 & $* * *$ \\
\hline UK & 2936 & 16.50 & 42.89 & 165.00 & 28.11 & -2.07 & & 27.33 & $* * *$ & 21.12 & $* * *$ & 23.19 & $* * *$ & 0.11 & $* * *$ \\
\hline Ukraine & 2936 & 1.00 & 2173.76 & 15028.76 & 3969.27 & -2.15 & & 60.42 & $* * *$ & 32.53 & $* * *$ & 17.13 & $* * *$ & 0.11 & $* * *$ \\
\hline USA & 2936 & 10.02 & 24.01 & 90.00 & 11.11 & -3.58 & * & 94.96 & $* * *$ & 46.67 & $* * *$ & 24.57 & $* * *$ & 0.18 & $* * *$ \\
\hline Venezuela & 2936 & 124.62 & 1771.08 & 10995.67 & 1869.79 & -2.00 & & 36.17 & $* * *$ & 38.56 & $* * *$ & 22.73 & $* * *$ & 0.11 & $* * *$ \\
\hline
\end{tabular}

Focusing on the evolution of the CDS log returns (computed as $x_{t}=\log \left(\frac{S_{t}}{S_{t-1}}\right)$ ) over the studied period, as presented in Figure 1, some volatility clustering periods are detected. Results of the ARCH-LM test in Table 2 confirm that the data used clearly exhibit heteroscedastic properties and support the appropriate use of GARCH-class processes to model the conditional volatility. The GPH test (Geweke and Porter-Hudak, 1983) conducted on the squared CDS log returns rejects the null hypothesis of no long-memory behavior in the series' volatility process, suggesting the use of the fractionally-integrated models ${ }^{[13]}$. Figure 2 reports the density estimation and show that the series, composing our international sample, exhibit dissimilar statistical behaviors as to their empirical distribution. The majority of the data returns distribution does not overlay the Gaussian reference, which indicates that the residuals should be allowed to follow a Gaussian, a student and a Generalized Error Distribution (G.E.D) ${ }^{[14]}$.

\footnotetext{
${ }^{[13]}$ Another commonly used long-range test is the Gaussian semi-parametric (GSP) (Robinson, 1995). Results of the GSP are not reported here because they are similar to those of the GPH.

${ }^{[14]}$ Other statistical distribution should, as well, be taken into account in further studies, such as the Skewed t-student...
} 


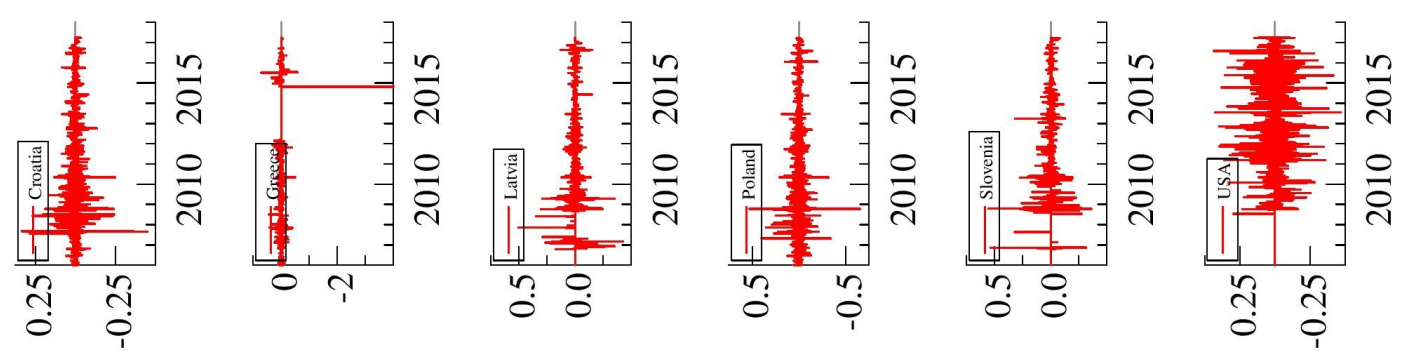

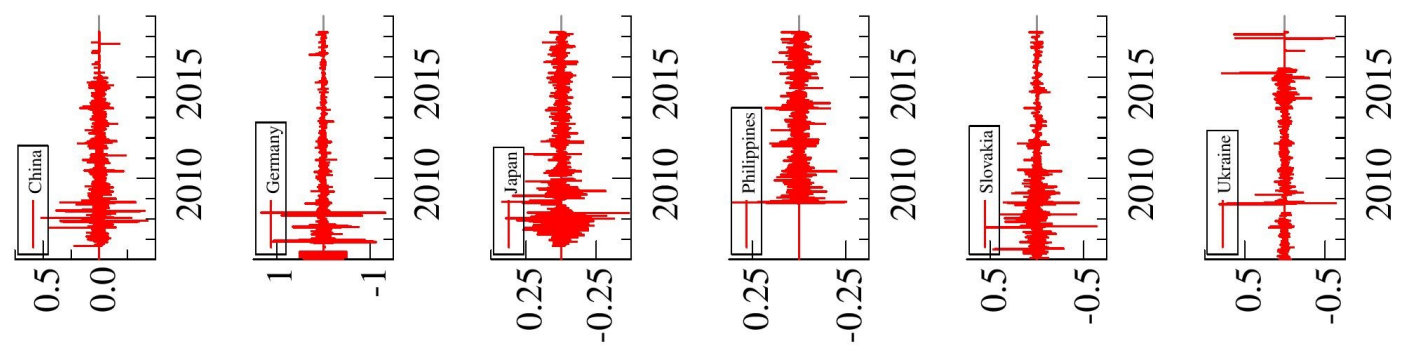
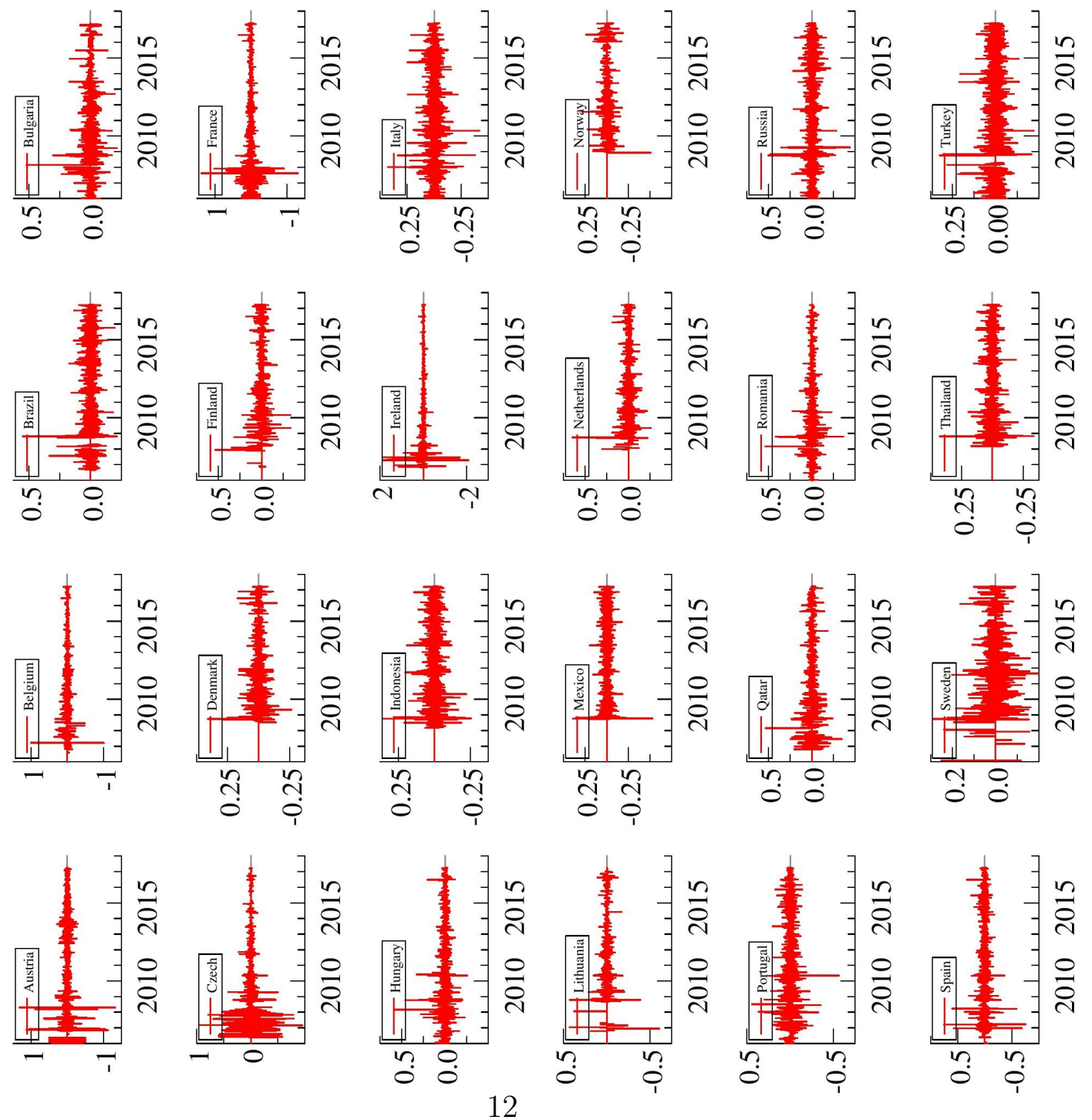

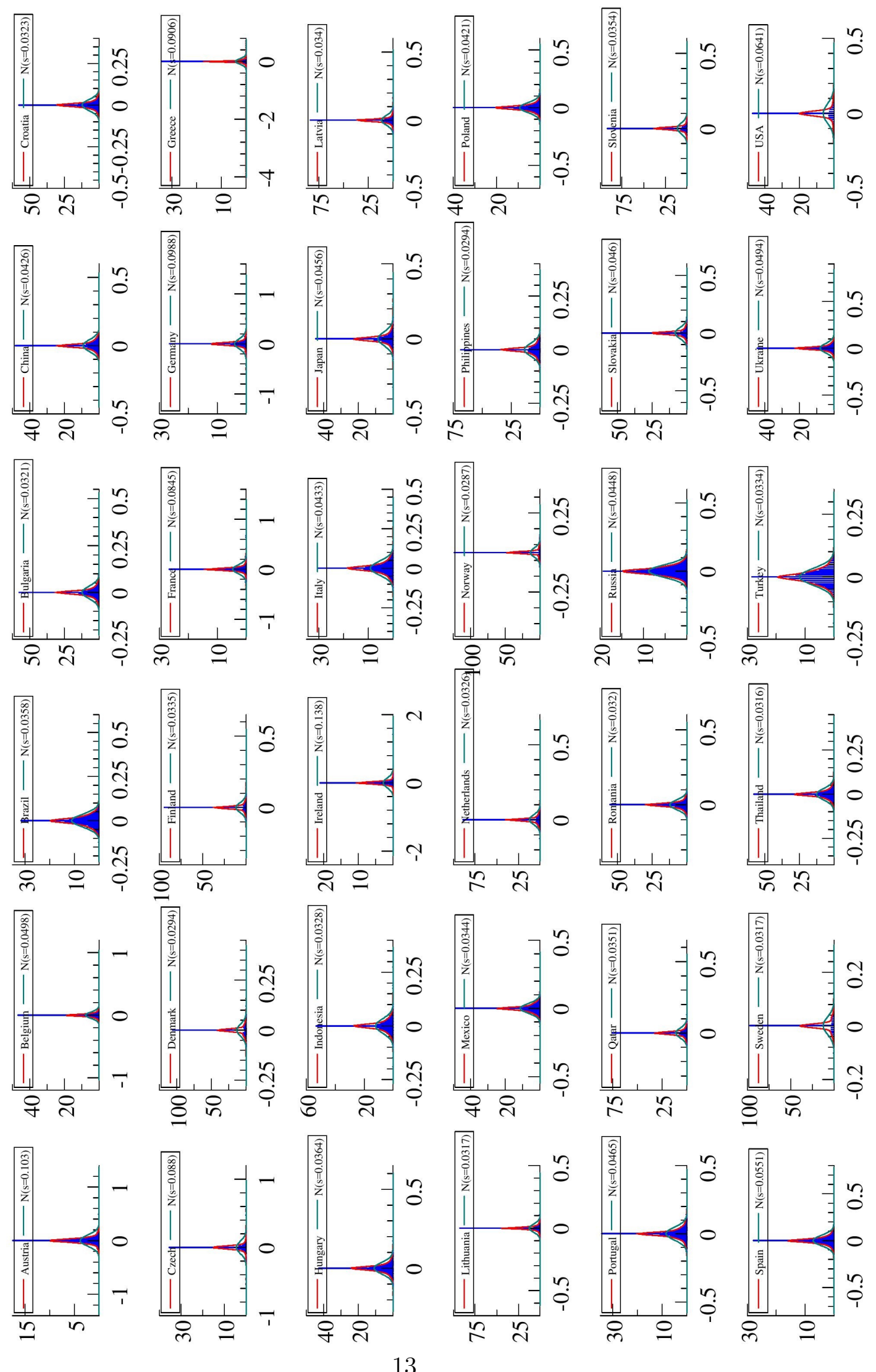

Figure 2: Daily CDS log returns for 38 worldwide countries 


\subsection{Models estimation and diagnostic tests}

Results of the 9 GARCH-class model estimates are not reported here but are available upon request. Even though some models are difficult to optimize, no miss-convergences are recorded for any time series. However, at first sight, the major conclusion that could be drawn regarding the models estimation process is that taking into account several financial markets' stylized facts (long memory characteristic, shock persistence and asymmetric leverage effects...) does not necessarily improve the models performances since the more the model is over-parametrized, the more its computation and its convergence are complicated. In fact, different inconsistency and inaccuracy of the estimator parameters in some countries and for some model can result from the complexity of the model's statistical specifications. At the opposite, the models that great perform as to strong numerical convergence and computing-time delay are the GARCH, the IGARCH, FIGARCH and FIEGARCH.

Results of the univariate misspecification tests applied on the standardized residuals are presented in Table 5 (Appendix A). The Q portmanteau empirical statistics with 20 lags of both standardized residuals in levels and squared show that the null hypothesis of no serial correlation is accepted in most cases for all the studied models. The LM-ARCH test up to 10 lag orders shows, as well, that there is no heteroscdasticity in the conditional variance equations of most of time series. The GARCH, IGARCH and FIGARCH models pass this in $100 \%$ of cases, whilst the least performant model, in terms of serial correlation, in the FIAPARCH with ARCH effects detected in 6 countries. Moreover, testing for conditional heteroscadticity through the Residual-Based Diagnostic (RDB) for conditional heteroscedasticity(Tse, 2002) gives better results, with absolutely no detected serial correlation in all series for the APARCH, IGARCH and FIGARCH. Based on the the Nyblom test, proposed by Nyblom (1989), no possible shifts are detected and the 9 models parameters coefficients are found to be constant over time for all countries. One of the recommended steps in modeling financial data process is to evaluate the goodness of fit (D'Agostino, 2017). The fitting of our models are thus assessed, in this paper, through the adjusted Pearson goodness-of-fit test. Statistics indicate that mostly there is no difference between the empirical distribution of the residuals and the theoretical one. Interestingly, the basic GARCH model seems to have the highest number (12 over the 38 studied series) of unconformity and discrepancy of the data from the data from the hypothesized probability distribution.

In addition to the diagnostic tests, Table 5 displays the Akaike information criterion (AIC) for each model and country. Result do not allow us to unanimously select only one most appropriate model. AIC results of the studied models are mitigated across the 38 countries of the sample. By minimizing the AIC, the APARCH turns out to be the best fitted model for the CDS data of $34 \%$ of the sample, while HYGARCH, IGARCH and FIAPARCH provide the best in-sample fit for respectively $26 \%, 18 \%$ and $11 \%$ of the studied countries. However, these results are not in line with the preliminary analysis where all the studied CDS log returns are found to be subject to long-memory feature in the variance. By only focusing in the fractionally integrated subset of models, the HYGARCH is found to majority outperform in $53 \%$ of cases, followed by the FIAPARCH in $40 \%$ of cases. These results divergence points out the limits of using the 'minimizing loss of information' technique in comparing models appropriateness. Thus, this approach seems to be, in this case, not totally consistent and should only be used tentatively, at least if it is not associated with any other 
approaches. Hence the importance of rather rely on the forecasting ability to select the best performant volatility model.

\subsection{Forecasting performance}

Results of the twenty-day out-of-sample volatility forecasts are reported in Table 3 and Table 4. As mentioned before, the forecasting robustness and reliability of the 9 models is studied through 7 error statistics, namely the MSE, MAE, HMSE, HMAE, QLIKE, R ${ }^{2}$ LOG and MLAE. Even though there is no unanimous dominant model in terms of forecasting ability according to all the comparison measure, it is clearly seen that the fractionallyintegrated class of model outperforms the basic GARCH models - not taking into account long-memory in volatility process. Ranked in the last position by 5 out of the 7 criteria, the least forecasting performant model for CDS volatility is the EGARCH with the largest recorded errors.

The lowest values of MSE, MAE and $\mathrm{R}^{2} \mathrm{LOG}$ are recorded for the FIGARCH, whilst the lowest values of HMSE, QLIKE and MLAE are reported for the FIEGARCH, making them preferable, in terms of accurate forecasting abilities, to the other studied models. On another side, and according to the results of the MSE, MAE, HMAE, R ${ }^{2} \mathrm{LOG}$ and MLAE criteria, the HYGARCH produce the highest errors, probably due to its computational complexity.

These findings empirically reveal the nonlinear predictability pattern of CDS volatility. In general, our results are in line with the findings of other financial markets: the non-linear GARCH-class models, that allows for leverage effects, nonsymmetrical dependencies and long-range memory in the volatility model provide a more accurate in-sample performance and a more reliable out-of-sample forecasting ability. The improvement of the forecasting power of the studied models depends, thus, on their ability to capture a maximum of financial stylized facts while estimating the CDS volatility of future days.

Table 4: Summary of the number of selected models according to each criterion

\begin{tabular}{|c|c|c|c|c|c|c|c|c|c|}
\hline & GARCH & EGARCH & GJR & APARCH & IGARCH & FIGARCH & FIEGARCH & FIAPARCH & HYGARCH \\
\hline MSE & 5 & 1 & 2 & 2 & 7 & 16 & 5 & 13 & 3 \\
\hline MAE & 4 & 0 & 1 & 0 & 3 & 14 & 6 & 11 & 4 \\
\hline HMSE & 3 & 3 & 2 & 2 & 2 & 4 & 10 & 7 & 9 \\
\hline HMAE & 4 & 3 & 2 & 4 & 3 & 6 & 7 & 11 & 1 \\
\hline QLIKE & 6 & 2 & 2 & 3 & 3 & 4 & 10 & 7 & 5 \\
\hline $\mathbf{R}^{2} \mathbf{L O G}$ & 5 & 2 & 2 & 1 & 3 & 9 & 6 & 8 & 5 \\
\hline MLAE & 2 & 3 & 0 & 3 & 0 & 6 & 18 & 5 & 4 \\
\hline
\end{tabular}

\section{Conclusion}

This paper aimed to assess the performances of 9 linear and non-linear volatility models. Using daily sovereign CDS data, GARCH, IGARCH, EGARCH, GJR, APARCH, FIGARCH, FIEGARCH, FIAPARCH and HYGARCH are estimated, allowing to take into account different financial markets properties such as the leverage effect, the asymmetric reaction to good and bad news and long-range persistence. The performance comparison being made upon several loss functions criteria and several multivariate diagnostic tests, a certain number of conclusions can be drawn. 
Table 3: Results of the loss functions criteria for the twenty-day out-of-sample volatility predictions

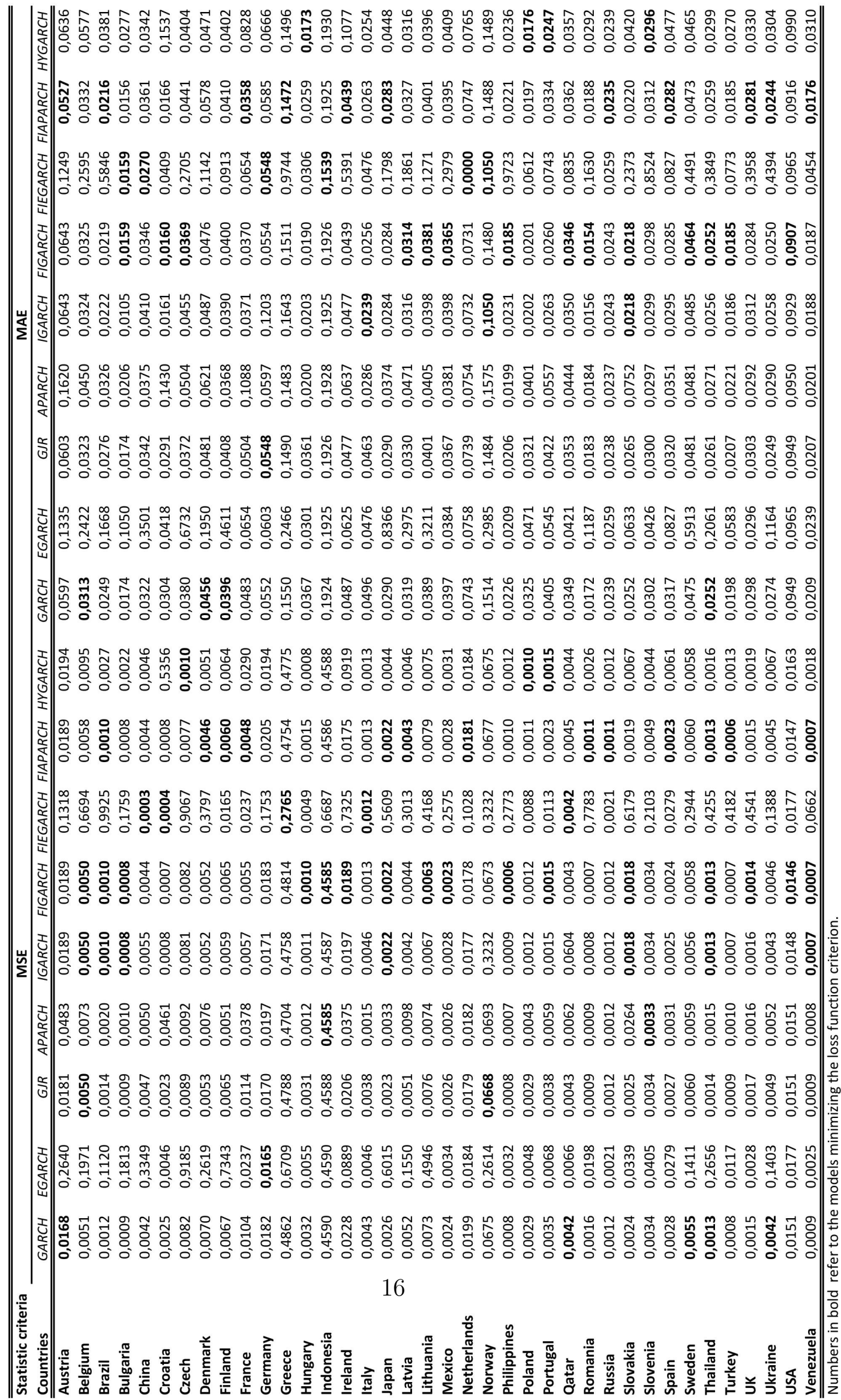


Table 3: Results of the loss functions criteria for the twenty-day out-of-sample volatility predictions (Continued)

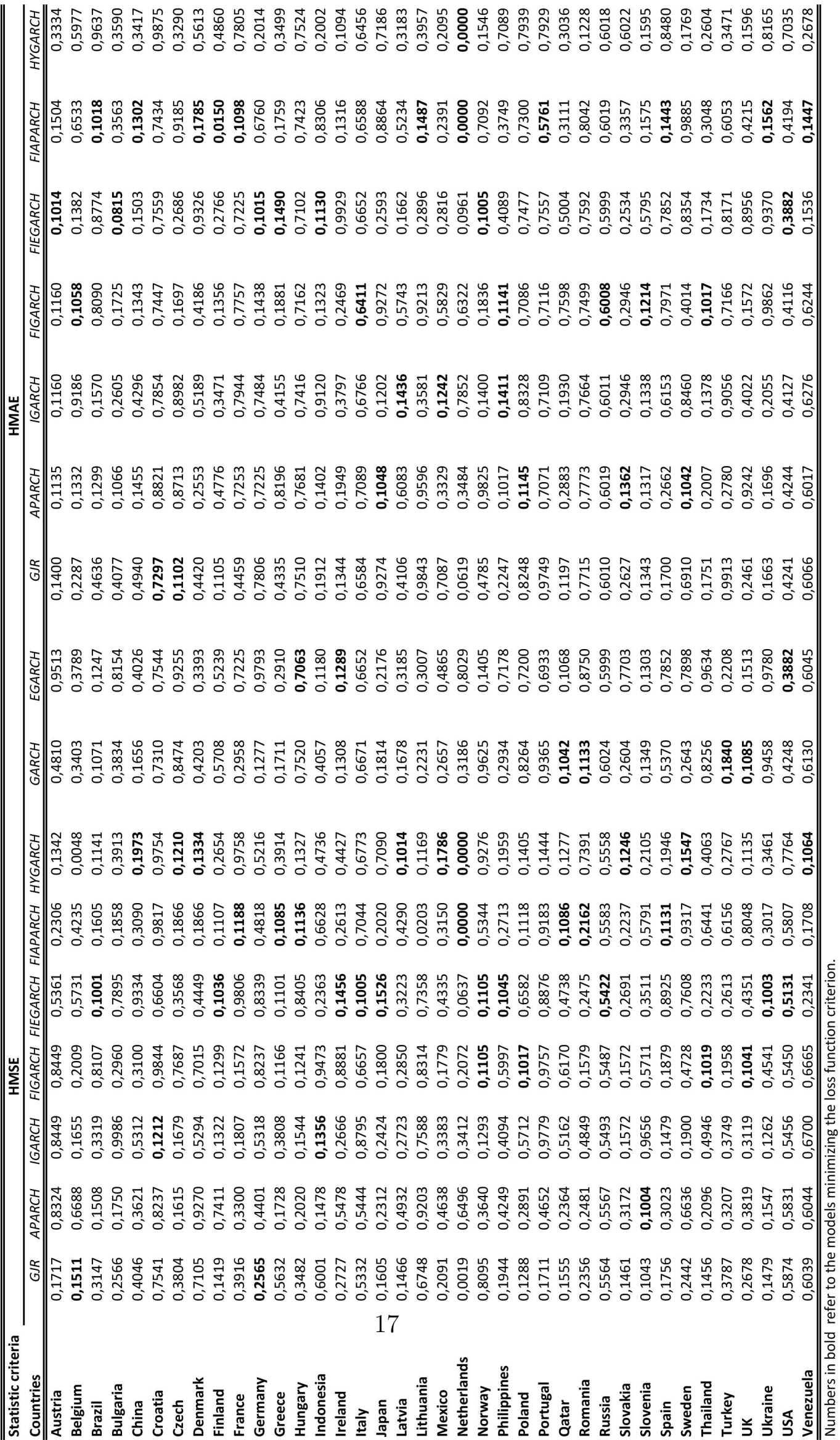


Table 3: Results of the loss functions criteria for the twenty-day out-of-sample volatility predictions (Continued)

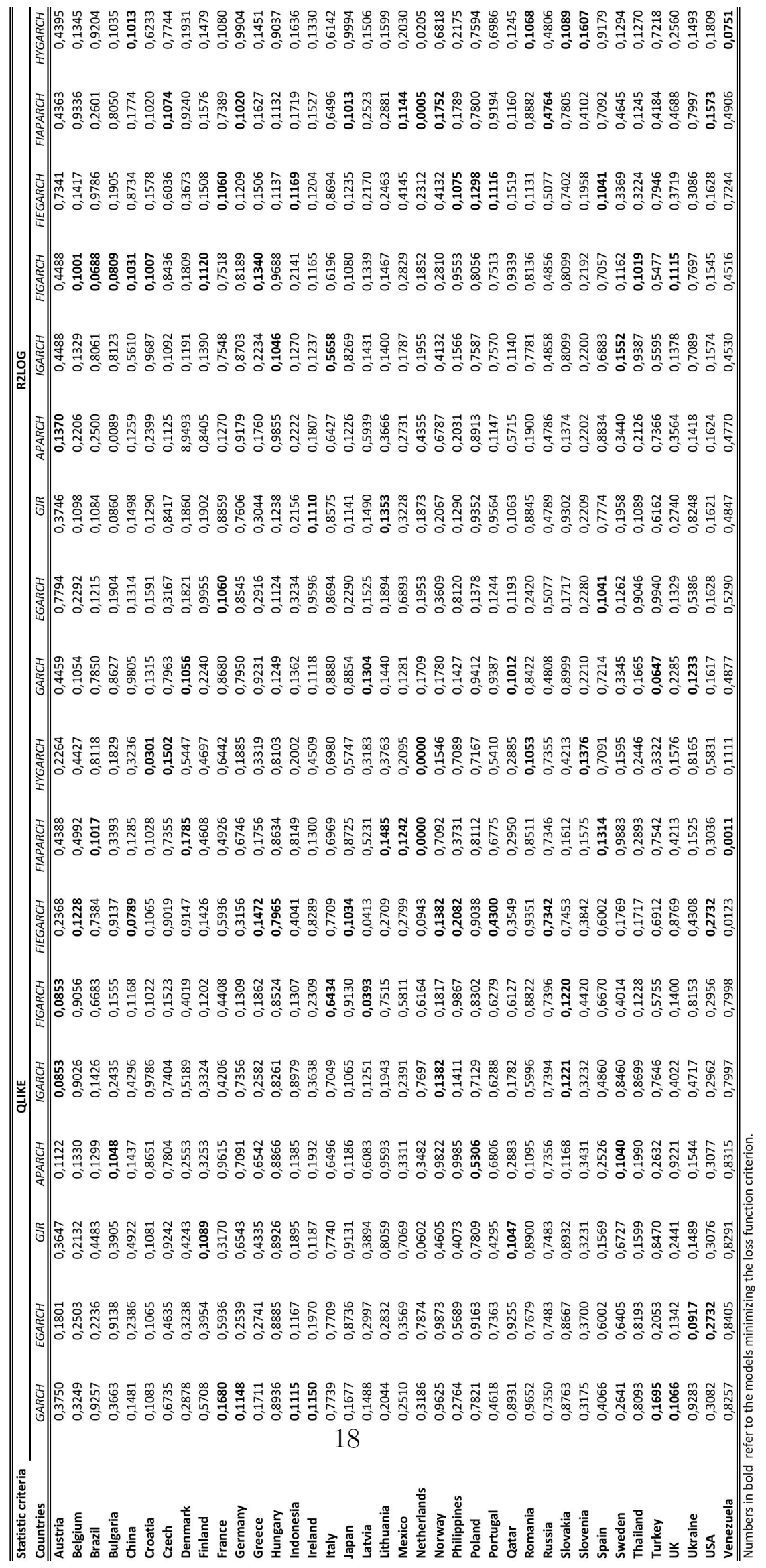


Table 3: Results of the loss functions criteria for the twenty-day out-of-sample volatility predictions (Continued)

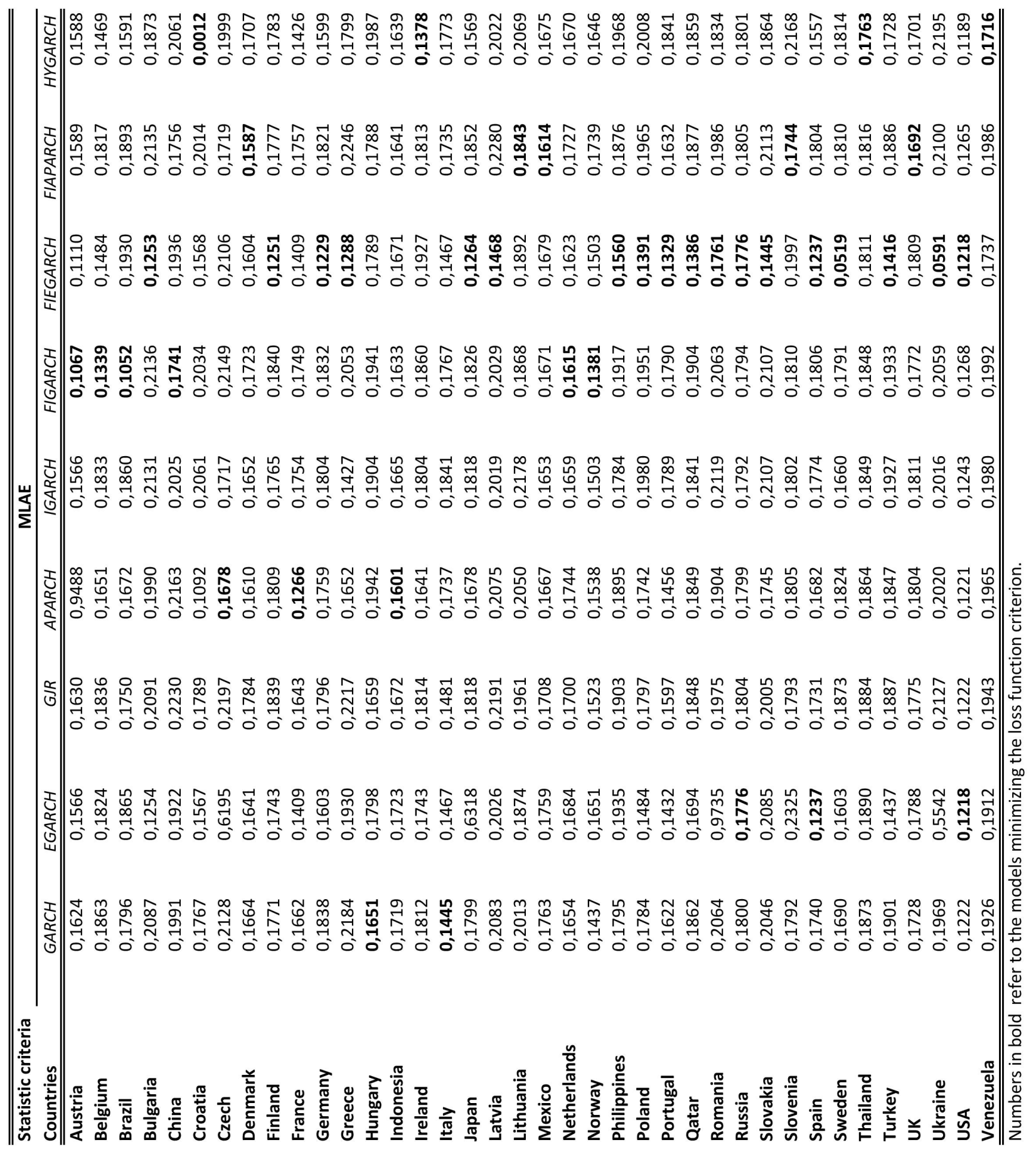


First, the in-sample estimation shows that all the models almost always pass all diagnostic tests for the most cases, and that the smallest Akaike criterion does not allow us to choose only one best fitted model. Second, none of the volatility models studied in this paper is found to be more relevant than all the others in all situations, in terms of forecasting ability. The chosen model varies from one country to another and from loss function criterion to another. Third, in most cases and according to the majority of the errors statistics criteria, the non-linear GARCH-class models, that capture the long-memory behavior, the leverage effects and the asymmetric dependencies in the volatility process are more relevant in terms of out-of-sample forecasting ability than the others. Fourth, the FIGARCH and FIEGARCH models are found to be the most relevant and robust forecasting models.

Since comparing predictive performance of volatility models is of a paramount in assessing diversifiable risk, in dynamic asset pricing theory and in optimization of portfolio allocation, the economic implication of our findings concerns particularly policymakers, financial practitioners and financial market participants generally. The in-sample performances show that no model clearly outperforms all the others, and since the results are mitigated and differ from one country to another, no volatility model should be selected in an arbitrary way. The model selection should rather be based on the particular features of the data used and the country studied. When it comes to the forecasting performances, some models are preferable and seem to predict accurately and robustly the future volatility of the CDS market. Thus, after taking into account the transaction costs, investors can eventually take advantage of the market's relative inefficiency and generate extra-profits by putting in place a simple trading strategy to exploit the predictability of sovereign CDS volatility. Finally, our study shows that improving the volatility forecasts needs including the maximum of CDS market's stylized facts. However, in practice, the implementation of complex models generates additional costs that are not necessarily reflected in our comparison method, which may controvert the usefulness of using better volatility predictive models.

Our research line can be pursued in several ways. First, a further investigation on the performances of the volatility models can be done by carrying out a comparative study based of the superior predictive ability test rather than on the diagnostic tests and loss functions criteria as in our case. Second, our study can be applied to the corporate CDS market, in order to assess whether the nature of the reference entity impacts the performances of the studied models. Third, since there is a dynamic segmentation in financial markets, it can be interesting to check the robustness of our findings using a different sample from other regions and/or a CDS term structure with different maturity.

\section{References}

Paolo Agnolucci. Volatility in crude oil futures: a comparison of the predictive ability of garch and implied volatility models. Energy Economics, 31(2):316-321, 2009. 3

Torben G Andersen, Tim Bollerslev, and Steve Lange. Forecasting financial market volatility: Sample frequency vis-a-vis forecast horizon. Journal of empirical finance, 6(5):457-477, 1999. 9

Davide Avino and Ogonna Nneji. Are cds spreads predictable? an analysis of linear and 
non-linear forecasting models. International Review of Financial Analysis, 34:262-274, 2014. 2,4

Richard T Baillie, Tim Bollerslev, and Hans Ole Mikkelsen. Fractionally integrated generalized autoregressive conditional heteroskedasticity. Journal of econometrics, 74(1):3-30, 1996. 3,7

Tim Bollerslev. Generalized autoregressive conditional heteroskedasticity. Journal of econometrics, 31(3):307-327, 1986. 3, 5

Tim Bollerslev and Eric Ghysels. Periodic autoregressive conditional heteroscedasticity. Journal of Business \&6 Economic Statistics, 14(2):139-151, 1996. 9

Tim Bollerslev and Hans Ole Mikkelsen. Modeling and pricing long memory in stock market volatility. Journal of econometrics, 73(1):151-184, 1996. 3, 8

Tim Bollerslev, Ray Y Chou, and Kenneth F Kroner. Arch modeling in finance: A review of the theory and empirical evidence. Journal of econometrics, 52(1-2):5-59, 1992. 4

Charles $\mathrm{G}$ Broyden. The convergence of a class of double-rank minimization algorithms: 2 . the new algorithm. IMA Journal of Applied Mathematics, 6(3):222-231, 1970. 8

Amélie Charles and Olivier Darné. Forecasting crude-oil market volatility: Further evidence with jumps. Energy Economics, 67:508-519, 2017. 3

Walid Chkili, Shawkat Hammoudeh, and Duc Khuong Nguyen. Volatility forecasting and risk management for commodity markets in the presence of asymmetry and long memory. Energy Economics, 41:1-18, 2014. 3

Mauro Costantini, Matteo Fragetta, and Giovanni Melina. Determinants of sovereign bond yield spreads in the emu: An optimal currency area perspective. European Economic Review, 70:337-349, 2014. 2, 4

Virginie Coudert and Mathieu Gex. The interactions between the credit default swap and the bond markets in financial turmoil. Review of International Economics, 21(3):492-505, 2013. 2,4

Virginie Coudert, Mathieu Gex, et al. Credit default swap and bond markets: which leads the other. Financial Stability Review, Banque de France, 14(2010):161167, 2010. 2, 4

RalphB D'Agostino. Goodness-of-fit-techniques. Routledge, 2017. 14

James Davidson. Moment and memory properties of linear conditional heteroscedasticity models, and a new model. Journal of Business 85 Economic Statistics, 22(1):16-29, 2004. 3,8

David A Dickey and Wayne A Fuller. Likelihood ratio statistics for autoregressive time series with a unit root. Econometrica: Journal of the Econometric Society, pages 1057-1072, 1981. 10 
Francis X Diebold and Robert S Mariano. Comparing predictive accuracy. Journal of Business $\&$ economic statistics, 20(1):134-144, 2002. 9

Zhuanxin Ding, Clive WJ Granger, and Robert F Engle. A long memory property of stock market returns and a new model. Journal of empirical finance, 1(1):83-106, 1993. 3, 7

Robert F Engle. Autoregressive conditional heteroscedasticity with estimates of the variance of united kingdom inflation. Econometrica: Journal of the Econometric Society, pages 987-1007, 1982. 3, 5

Robert F Engle and Tim Bollerslev. Modelling the persistence of conditional variances. Econometric reviews, 5(1):1-50, 1986. 3, 6

Dean Fantazzini. Fractionally integrated models for volatility: A review-empirical appendix: Some examples with $\mathrm{r}$ interfaced with the ox package g@rch. In Nonlinear Financial Econometrics: Markov Switching Models, Persistence and Nonlinear Cointegration, pages 104-123. Springer, 2011. 8

Miguel A Ferreira and Pedro Santa-Clara. Forecasting stock market returns: The sum of the parts is more than the whole. Journal of Financial Economics, 100(3):514-537, 2011. 3

Alessandro Fontana and Martin Scheicher. An analysis of euro area sovereign cds and their relation with government bonds. Journal of Banking \&f Finance, 62:126-140, 2016. 2, 4

John Geweke and Susan Porter-Hudak. The estimation and application of long memory time series models. Journal of time series analysis, 4(4):221-238, 1983. 11

Lawrence R Glosten, Ravi Jagannathan, and David E Runkle. On the relation between the expected value and the volatility of the nominal excess return on stocks. The journal of finance, 48(5):1779-1801, 1993. 3, 7

Massimo Guidolin, Stuart Hyde, David McMillan, and Sadayuki Ono. Non-linear predictability in stock and bond returns: When and where is it exploitable? International Journal of Forecasting, 25(2):373-399, 2009. 3

Donald B Keim and Robert F Stambaugh. Predicting returns in the stock and bond markets. Journal of financial Economics, 17(2):357-390, 1986. 3

CNV Krishnan, Peter H Ritchken, and James B Thomson. Predicting credit spreads. Journal of Financial Intermediation, 19(4):529-563, 2010. 2, 4

Francis A Longstaff, Jun Pan, Lasse H Pedersen, and Kenneth J Singleton. How sovereign is sovereign credit risk? American Economic Journal: Macroeconomics, 3(2):75-103, 2011. 2,4

Jose Lopez. Evaluating the predictive accuracy of volatility models. Journal of Forecasting, 20(2):87-109, 2001. 10 
Jacob A Mincer and Victor Zarnowitz. The evaluation of economic forecasts. In Economic forecasts and expectations: Analysis of forecasting behavior and performance, pages 3-46. NBER, 1969. 10

JP Morgan. Reuters (1996). RiskMetrics-Technical Document, 4, 1996. 6

Daniel B Nelson. Conditional heteroskedasticity in asset returns: A new approach. Econometrica: Journal of the Econometric Society, pages 347-370, 1991. 3, 7

Hongli Niu and Jun Wang. Volatility clustering and long memory of financial time series and financial price model. Digital Signal Processing, 23(2):489-498, 2013. 2, 3

Jukka Nyblom. Testing for the constancy of parameters over time. Journal of the American Statistical Association, 84(405):223-230, 1989. 8, 14

Luís Oliveira, José Dias Curto, and João Pedro Nunes. The determinants of sovereign credit spread changes in the euro-zone. Journal of International Financial Markets, Institutions and Money, 22(2):278-304, 2012. 2, 4

Adrian R Pagan and G William Schwert. Alternative models for conditional stock volatility. Journal of econometrics, 45(1-2):267-290, 1990. 10

Franz C Palm and Peter JG Vlaar. Simple diagnostic procedures for modeling financial time series. Technical report, Maastricht University, 1997. 9

Keith Pilbeam and Kjell Noralf Langeland. Forecasting exchange rate volatility: Garch models versus implied volatility forecasts. International Economics and Economic Policy, 12(1):127-142, 2015. 9

Ser-Huang Poon. A practical guide to forecasting financial market volatility. John Wiley \& Sons, 2005. 2, 3, 9, 10

Peter M Robinson. Log-periodogram regression of time series with long range dependence. The annals of Statistics, pages 1048-1072, 1995. 11

Saker Sabkha, Christian De Peretti, and Dorra Hmaied. International risk spillover in the sovereign credit markets: An empirical analysis. Working paper, 2017. 2, 4

Susan Sunila Sharma and Kannan Thuraisamy. Oil price uncertainty and sovereign risk: Evidence from asian economies. Journal of Asian Economics, 28:51-57, 2013. 2, 4

Sasha Srivastava, Hai Lin, Inguruwatte M Premachandra, and Helen Roberts. Global risk spillover and the predictability of sovereign cds spread: International evidence. International Review of Economics \& Finance, 41:371-390, 2016. 2, 4

Yiu Kuen Tse. The conditional heteroscedasticity of the yen-dollar exchange rate. Journal of Applied Econometrics, pages 49-55, 1998. 3, 8

Yiu Kuen Tse. Residual-based diagnostics for conditional heteroscedasticity models. The Econometrics Journal, 5(2):358-374, 2002. 9, 14 
Yu Wei, Yudong Wang, and Dengshi Huang. Forecasting crude oil market volatility: Further evidence using garch-class models. Energy Economics, 32(6):1477-1484, 2010. 3, 5, 9, 10

Jean-Michel Zakoian. Threshold heteroskedastic models. Journal of Economic Dynamics and control, 18(5):931-955, 1994. 7

\section{A Appendix}


Table 5: Results of the diagnostic tests for the 38 countries (Continued)

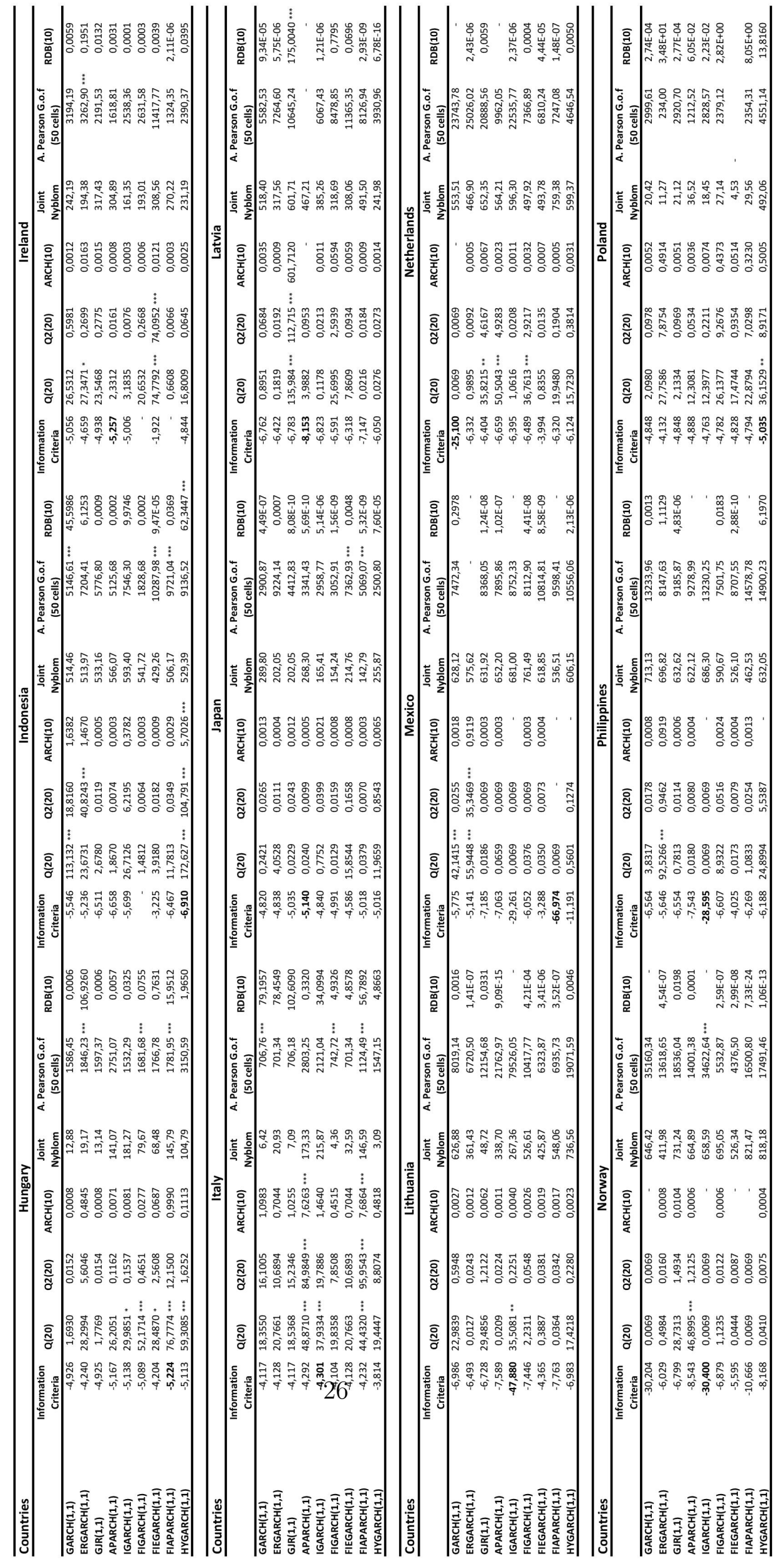


Table 5: Results of the diagnostic tests for the 38 countries (Continued)

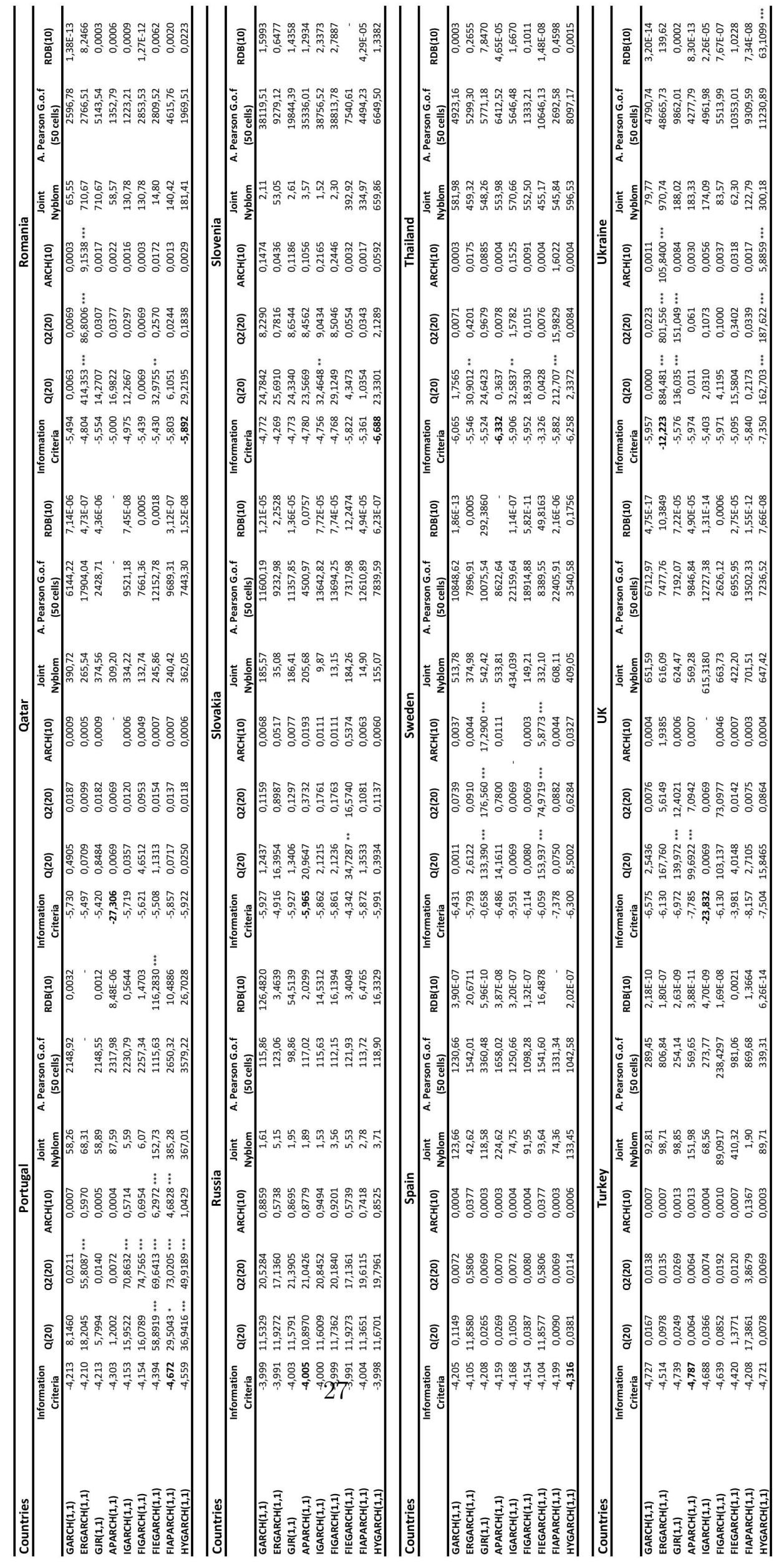


Table 5: Results of the diagnostic tests for the 38 countries (Continued)

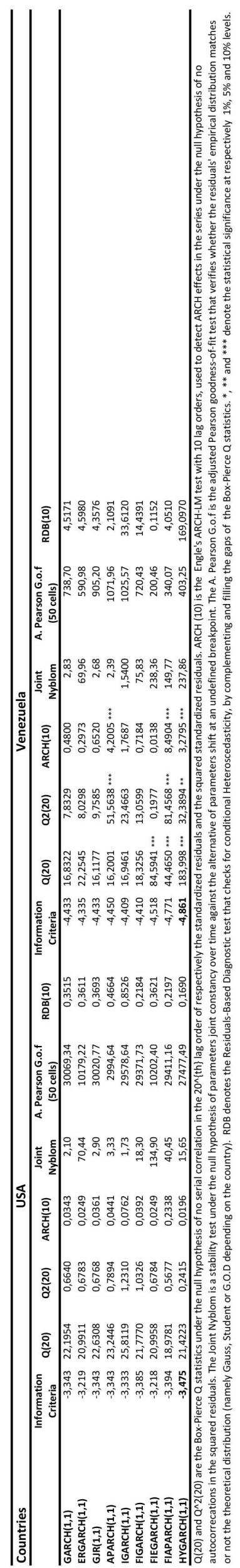

